\title{
Impact of obstructive sleep apnoea on left ventricular mass and global function
}

\author{
D. Dursunoglu*, N. Dursunoglu\#", H. Evrengül*, S. Özkurt", Ö. Kuru*, \\ M. Kiliç* and F. Fisekci ${ }^{\#}$
}

ABSTRACT: Obstructive sleep apnoea syndrome (OSAS) might be a cause of heart failure. The present study aimed to assess left ventricular mass and myocardial performance index (MPI) in OSAS patients.

A total of 67 subjects without any cardiac or pulmonary disease, referred for evaluation of OSAS, had overnight polysomnography and echocardiography. According to apnoea-hypopnoea index $(\mathrm{AHI})$, subjects were classified into three groups: mild OSAS (AHI: 5-14; $n=16)$, moderate OSAS (AHI: 15-29; $n=18$ ), and severe OSAS (AHI: $\geqslant 30 ; n=33$ ). Thickness of interventricular septum (IVS) and posterior wall (LVPW) were measured by M-mode, along with left ventricular mass (LVM) and LVM index (LVMI). Left ventricular MPI was calculated as (isovolumic contraction time+isovolumic relaxation time)/aortic ejection time by Döppler echocardiography.

There were no differences in age or body mass index among the groups, but blood pressures were higher in severe OSAS compared with moderate and mild OSAS. In severe OSAS, thickness of IVS $(11.2 \pm 1.1 \mathrm{~mm})$, LVPW $(11.4 \pm 0.9 \mathrm{~mm})$, LVM $(298.8 \pm 83.1 \mathrm{~g})$ and LVMI $\left(144.7 \pm 39.8 \mathrm{~g} \cdot \mathrm{m}^{-2}\right)$ were higher than in moderate OSAS $(10.9 \pm 1.3 \mathrm{~mm} ; 10.8 \pm 0.9 \mathrm{~mm} ; 287.3 \pm 74.6 \mathrm{~g}$; $126.5 \pm 41.2 \mathrm{~g} \cdot \mathrm{m}^{-2}$, respectively) and mild OSAS $(9.9 \pm 0.9 \mathrm{~mm} ; 9.8 \pm 0.8 \mathrm{~mm} ; 225.6 \pm 84.3 \mathrm{~g}$; $100.5 \pm 42.3 \mathrm{~g} \cdot \mathrm{m}^{-2}$, respectively). In severe OSAS, MPI $(0.64 \pm 0.14)$ was significantly higher than in mild OSAS $(0.50 \pm 0.09)$, but not significantly higher than moderate OSAS $(0.60 \pm 0.10)$.

In conclusion, severe and moderate obstructive sleep apnoea syndrome patients had higher left ventricular mass and left ventricular mass index, and also left ventricular global dysfunction.

KEYWORDS: Left ventricular mass, myocardial performance index, obstructive sleep apnoea syndrome

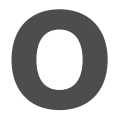
bstructive sleep apnoea syndrome (OSAS) is characterised by repetitive collapse of the upper airway during sleep [1]. The obstructive apnoeic event is associated with considerable breathing efforts against a totally or partially occluded upper airway, and apnoea is terminated by an arousal and heavy snoring as airflow is restored. Severity of OSAS is described according to total number of apnoeas and hypopnoeas per hour of sleep, which is named as the apnoea-hypopnoea index (AHI).

Cardiovascular disturbances are the most serious complications of OSAS [2]. These complications include heart failure [3], acute myocardial infarction [4], nocturnal arrhythmias [5], stroke [6], systemic [7, 8] and pulmonary hypertension [9]. All these cardiovascular complications increase morbidity and mortality of OSAS. Currently, sleep apnoea is accepted as one of the identifiable causes of hypertension [10]. Also, OSAS is closely associated with obesity [11] and ageing [12].
OSAS contributes to the development of left ventricular hypertrophy (LVH) [13]. The proposed causes include associated changes in left ventricular afterload, intermittent hypoxaemia, and recurrent arousals during sleep. LVH is a major independent risk factor for morbidity and mortality from cardiovascular disease $[14,15,16]$. It was shown that many subjects with $\mathrm{LVH}$ have normal blood pressure, suggesting that factors other than haemodynamic overload may contribute to the hypertrophy [17]. Diastolic dysfunction precedes left ventricular systolic impairment and accounts for $\sim 30-40 \%$ of patients with left ventricular failure alone [18, 19]. Early recognition and appropriate therapy of left ventricular diastolic dysfunction (LVDD) is advisable to prevent further progression to heart failure and death [18, 19]. Since systolic and diastolic dysfunctions frequently coexist, it was shown that a combined measure of left ventricular performance might be more reflective of overall
AFFILIATIONS

Depts of *Cardiology and

\#Chest Disease, Pamukkale University Medical Faculty, Denizli, Turkey.

CORRESPONDENCE

D. Dursunoglu

Yunus Emre Mah. Huseyin Yilmaz cad.

No:1414

Kinikli

Denizli

Turkey

Fax: 902582410040

E-mail:

dursundursunoglu@yahoo.com

Received

March 312004

Accepted after revision:

April 292005 
cardiac dysfunction than systolic or diastolic measures alone $[20,21]$. The left ventricular myocardial performance index (MPI) reflects both systolic and diastolic left ventricular functions (global functions). In the presence of global dysfunction of the left ventricle, MPI increases in contrast to ejection fraction (EF) of the left ventricle. MPI is a reproducible, widely applicable and a simple noninvasive method for the estimation of left ventricular global function in the patients.

In the present study, the current authors aimed to estimate the left ventricular mass (LVM) and global function in OSAS patients, and evaluated the relationship between MPI and AHI.

\section{METHODS}

\section{Study population}

To be eligible, all of the 92 subjects admitted to the sleep clinic with symptoms of nocturnal snoring and/or excessive daytime sleepiness had to fulfil the following criteria: absence of 1) any known cardiac and lung disease; 2) diabetes mellitus; 3) angina pectoris; 4) atrial fibrillation or any arrhythmias; 5) chronic renal and hepatic diseases; and 6) serum electrolytes imbalances.

A total of 67 out of 92 subjects were admitted to the study. A detailed sleep and cardiovascular history of the patients were recorded. Sleep cycle, nutritional status, medications, alcohol usage and family anamnesis were also questioned. Epworth sleepiness scale (ESS) [22] was assessed in all patients, and patients having high scores $(E S S \geqslant 10)$ were taken into the sleep study.

Physical examination was performed in all subjects. Systolic and diastolic blood pressures (SBP and DBP, respectively) were measured consecutively in the sitting position on the right arm using a sphygmomanometer (Erka, Bad Tölz, Germany), after $\geqslant 5 \mathrm{~min}$ of rest. Hypertension was defined as a blood pressure $\geqslant 140 / 90 \mathrm{mmHg}$ or by the use of antihypertensive drugs. However, all hypertensive patients in the study group were taking antihypertensive medication. Heart rate (HR) per minute was measured in the sitting position, and body mass index (BMI) of the patients were calculated as weight divided by height square $\left(\mathrm{kg} \cdot \mathrm{m}^{-2}\right)$.

Pulmonary function tests (SensorMedics 2400; SensorMedics, Bilthoven, The Netherlands), arterial blood gas analysis (ABL 30; Radiometer, Copenhagen, Denmark) were performed in all patients at rest. A 12-lead surface ECG was taken from every subject, and all of them were in sinus rhythm. All subjects also underwent a treadmill exercise test and the test was normal for each subject.

\section{Polysomnography}

Polysomnography was applied to all subjects on the night of diagnosis [23]. The portable, limited sleep study performed with the Embletta device (Flaga hf. Medical Devices, Reykjavik, Iceland; distribution by ResMed) [24], consisted of the following: 1) nasal pressure detector using nasal cannulae/ pressure transducer system, recording the square root of pressure as an index of flow; 2) thoraco-abdominal movement detection through two piezoelectric belts; 3) finger pulse oximeter; and 4) body position detection.
Apnoea was defined as a total obstruction of oronasal airflow for $\geqslant 10 \mathrm{~s}$, hypopnoea was defined as a decrease of airflow of $\geqslant 50 \%$, and desaturations were accepted as a $\geqslant 4 \%$ decrease in oxygen saturation [25]. Desaturation index (DI) was defined as the number of oxygen desaturation events per hour of sleep. Subjects with an AHI $\geqslant 5$ were diagnosed as having OSAS [26]. Patients with OSAS were divided into three groups according to AHI: mild OSAS (AHI: 5-14; $n=16$ ), moderate OSAS (AHI: 15-29; $n=18$ ), and severe OSAS (AHI: $\geqslant 30 ; n=33$ ).

\section{Echocardiographic measurements}

All measurements were performed with the subjects in the left lateral decubitus position by M-mode, two dimensional, and Döppler ultrasound echocardiography. The ultrasound equipment used was Contron Sigma Iris (Contron Medical, Paris, France) with a $2.5-\mathrm{MHz}$ probe. The duration of the examination was $\geqslant 20 \mathrm{~min}$. The ventricular diameters, volumes and functions were measured according to the recommendations of the American Society of Echocardiography [27]. Basic measurements of left ventricular dimensions in diastole and systole, thickness of interventricular septum (IVS), left ventricular posterior wall (LVPW) and LVM were measured by the M-mode technique and LVM was divided with body surface area to obtain LVM index (LVMI). Left ventricular EF by Simpson's method was calculated as:

$$
\text { (diastolic volume-systolic volume)/diastolic volume }
$$

Early (E) and atrial (A) transmitral maximal flow velocities, the ratio $(\mathrm{E} / \mathrm{A})$ and deceleration time of $\mathrm{E}$-wave were registered. Isovolumic relaxation time (IVRT) was measured by the continuous wave Döppler technique. The velocity of mitral flow propagation was estimated using colour Döppler Mmode. The left ventricular MPI was calculated as:

(isovolumic contraction time + IVRT)/aortic ejection time

\section{Statistical analysis}

Data are presented as mean $\pm \mathrm{SD}$, and the Kruskal-Wallis test was used for group comparisons. Mann-Whitney U-test was used when only two groups were compared. A p-value $<0.05$ was considered statistically significant.

\section{RESULTS}

A total of 56 males (83.6\%) and 11 females (16.4\%) were included in the study. None were using alcohol, but $62 \%$ of them were smoking cigarettes. The mean ESS score of the study population was $17.2 \pm 5.1$ (range 10-23). Basic characteristics of the patients with OSAS are shown in table 1. There were no significant differences in their age, sex, BMI, and HR among the OSAS patients $(\mathrm{p}>0.05)$. However, SBP and DBP were higher in the severe OSAS patients than moderate and mild OSAS patients. Of 67 OSAS patients, 38 were hypertensive, and the majority $(68.4 \%)$ were in the severe group. As usual, AHI and DI were the highest in patients with severe OSAS $(\mathrm{p}<0.0001)$, and, in contrast, these patients had both the lowest average and minimum nocturnal saturation of arterial oxygen $\left(\mathrm{S}_{\mathrm{a}}, \mathrm{O}_{2}\right)(\mathrm{p}<0.0001)$. Percentage of sleep duration at $<90 \% \mathrm{Sa}_{1} \mathrm{O}_{2}$ was significantly higher in the severe OSAS group, while it was the lowest in the mild OSAS group. 


\begin{tabular}{|c|c|c|c|c|}
\hline \multirow[t]{3}{*}{ TABLE 1} & \multicolumn{4}{|c|}{$\begin{array}{l}\text { sic characteristics of the patients with } \\
\text { structive sleep apnoea syndrome (OSAS) }\end{array}$} \\
\hline & \multicolumn{4}{|c|}{ Patients with OSAS } \\
\hline & AHI 5-14 & AHI 15-29 & $A H I \geqslant 30$ & $\mathrm{p}$-value \\
\hline Subjects n & 16 & 18 & 33 & \\
\hline Mean age yrs & $46.0 \pm 5.6$ & $46.5 \pm 4.9$ & $48.1 \pm 6.5$ & NS \\
\hline Male n (\%) & $13(81.3)$ & 15 (83.3) & $28(84.8)$ & NS \\
\hline Female n (\%) & $3(18.7)$ & $3(16.7)$ & 5 (15.2) & NS \\
\hline BMI $\mathbf{k g} \cdot \mathbf{m}^{-2}$ & $29.3 \pm 2.4$ & $30.4 \pm 4.0$ & $30.6 \pm 3.7$ & NS \\
\hline SBP mmHg & $115.0 \pm 24.5$ & $122.2 \pm 8.3$ & $136.3 \pm 15.7$ & 0.001 \\
\hline DBP mmHg & $77.5 \pm 17.3$ & $83.3 \pm 5.0$ & $89.7 \pm 9.3$ & 0.01 \\
\hline HR pulse $\cdot \mathrm{min}^{-1}$ & $77.3 \pm 9.1$ & $76.1 \pm 10.7$ & $86.4 \pm 13.4$ & NS \\
\hline Hypertension n (\%) & $4(25)$ & $8(44.4)$ & $26(61.9)$ & 0.004 \\
\hline AHI per $h$ & $5.2 \pm 2.8$ & $25.3 \pm 2.6$ & $50.1 \pm 11.6$ & 0.0001 \\
\hline DI per $h$ & $9.2 \pm 4.5$ & $18.8 \pm 12.1$ & $37.8 \pm 18.0$ & 0.0001 \\
\hline Minimum $\mathrm{Sa}, \mathrm{O}_{2} \%$ & $83.8 \pm 5.7$ & $78.2 \pm 7.6$ & $73.8 \pm 18.9$ & 0.0001 \\
\hline Average $\mathrm{Sa}, \mathrm{O}_{2} \%$ & $94.1 \pm 3.2$ & $85.2 \pm 5.9$ & $80.3 \pm 11.4$ & 0.0001 \\
\hline Sleep duration \% ${ }^{\#}$ & 2.1 & 42.3 & 55.4 & 0.0001 \\
\hline \multicolumn{5}{|c|}{$\begin{array}{l}\text { Data are presented as } n, n(\%) \text { or mean } \pm \mathrm{SD} \text {. AHI: apnoea-hypopnoea index; } \\
\text { BMI: body mass index; SBP: systolic blood pressure; DBP: diastolic blood } \\
\text { pressure; HR: heart rate; DI: desaturation index; } \mathrm{Sa}_{2} \mathrm{O}_{2} \text { : saturation of nocturnal } \\
\text { arterial oxygen; NS: nonsignificant. } \# \text { : at } \mathrm{Sa}_{1} \mathrm{O}_{2}<90 \% \text {. }\end{array}$} \\
\hline
\end{tabular}

Basic echocardiographic measurements of the left ventricle in patients with OSAS are shown in table 2. While left ventricular end-diastolic and end-systolic diameters were not statistically different among groups of OSAS patients, left atrial diameter was significantly higher in severe OSAS patients compared with mild OSAS patients $(\mathrm{p}<0.01)$. In severe OSAS patients, thickness of IVS $(11.2 \pm 1.1 \mathrm{~mm}), \mathrm{LVPW}(11.4 \pm 0.9 \mathrm{~mm}), \mathrm{LVM}$ $(298.8 \pm 83.1 \mathrm{~g})$ and LVMI $\left(144.7 \pm 39.8 \mathrm{~g} \cdot \mathrm{m}^{-2}\right)$ were higher than both moderate OSAS $(10.9 \pm 1.3 \mathrm{~mm} ; 10.8 \pm 0.9 \mathrm{~mm} ; 287.3 \pm$ $74.6 \mathrm{~g} ; 126.5 \pm 41.2 \mathrm{~g} \cdot \mathrm{m}^{-2}$, respectively) and mild OSAS patients $\left(9.9 \pm 0.9 \mathrm{~mm} ; 9.8 \pm 0.8 \mathrm{~mm} ; 225.6 \pm 84.3 \mathrm{~g} ; 100.5 \pm 42.3 \mathrm{~g} \cdot \mathrm{m}^{-2}\right.$, respectively). Basic measurements in the different OSAS groups are shown in table 3.

The left ventricular systolic and diastolic functions in patients with OSAS were shown in table 4 . Left ventricular systolic functions (EF and fractional shortening) were not significantly different in three groups of OSAS patients, and were in normal limits. While mild OSAS patients had normal left ventricular diastolic functions, whereas moderate and severe OSAS patients had LVDD. The left ventricular MPI was significantly higher in severe OSAS patients $(0.64 \pm 0.14)$ than in mild OSAS patients $(0.50 \pm 0.09 ; \mathrm{p}<0.01)$. Also, MPI was statistically different between moderate $(0.60 \pm 0.10)$ and mild OSAS patients $(0.50 \pm 0.09 ; \mathrm{p}<0.01)$, but it was not statistically different between severe and moderate OSAS patients $(\mathrm{p}>0.05)$.

A positive correlation was shown between left ventricular MPI and AHI, reflecting severity of OSAS $(p<0.001, r=0.825)$. Correlation between MPI and AHI in OSAS patients is shown in figure 1. Cumulative time (h) with $\mathrm{Sa}_{1} \mathrm{O}_{2}<90 \%$ of all OSAS patients was calculated as $3.4 \pm 1.2 \mathrm{~h}$, and it was positively

\begin{tabular}{|c|c|c|c|c|c|}
\hline \multirow[t]{3}{*}{ TABLE 2} & \multicolumn{5}{|c|}{$\begin{array}{l}\text { Basic echocardiographic measurements of the left } \\
\text { ventricle in patients with obstructive sleep apnoea } \\
\text { syndrome (OSAS) }\end{array}$} \\
\hline & & \multicolumn{4}{|c|}{ Patients with OSAS } \\
\hline & & AHI 5-14 & AHI 15-29 & $A H I \geqslant 30$ & p-value \\
\hline Subjects $n$ & & 16 & 18 & 33 & \\
\hline \multicolumn{6}{|c|}{$\begin{array}{l}\text { Thickness and } \\
\text { diameters } \mathrm{mm}\end{array}$} \\
\hline Left atrium & $19-40$ & $32.8 \pm 2.3$ & $34.6 \pm 6.4$ & $36.1 \pm 5.7$ & 0.02 \\
\hline IVSD $^{\#} 6-1$ & & $9.9 \pm 0.9$ & $10.9 \pm 1.3$ & $11.2 \pm 1.1$ & 0.001 \\
\hline PLVWD ${ }^{\#} 6$ & & $9.8 \pm 0.8$ & $10.8 \pm 0.9$ & $11.4 \pm 0.9$ & 0.001 \\
\hline LVEDD $^{\#} 3$ & & $47.8 \pm 6.6$ & $49.5 \pm 4.6$ & $50.6 \pm 5.6$ & NS \\
\hline LVESD $^{\#} 1$ & & $30.5 \pm 5.6$ & $32.1 \pm 4.0$ & $33.2 \pm 4.8$ & NS \\
\hline \multicolumn{6}{|c|}{ Left ventricular mass } \\
\hline LVM $^{\#, 9} \mathrm{~g}$ & & $225.6 \pm 84.3$ & $287.3 \pm 74.6$ & $298.8 \pm 83.1$ & 0.0001 \\
\hline $\mathrm{LVMI}^{\#,+} \mathrm{g}$. & & $100.5 \pm 42.3$ & $126.5 \pm 41.2$ & $144.7 \pm 39.8$ & 0.004 \\
\hline \multicolumn{6}{|c|}{$\begin{array}{l}\text { Data are presented as mean } \pm \text { SD or } \mathrm{n} \text {. AHI: apnoea-hypopnoea index; IVSD: } \\
\text { interventricular septum thickness in diastole; PLVWD: posterior left ventricular } \\
\text { wall thickness in diastole; LVEDD: left ventricular end-diastolic diameter; } \\
\text { LVESD: left ventricular end-systolic diameter; LVM: left ventricular mass; LVMI: } \\
\text { left ventricular mass index. }{ }^{\#}: \text { normal values; }{ }^{\bullet}<198 \text { in females, }<294 \text { in } \\
\text { males; }^{+}:<110 \text { in females, }<134 \mathrm{~g} \cdot \mathrm{m}^{-2} \text { in males; NS: nonsignificant. }\end{array}$} \\
\hline
\end{tabular}

correlated with left ventricular MPI $(r=0.847, p<0.001)$. Correlation between cumulative time (h) with $\mathrm{Sa}_{\mathrm{a}} \mathrm{O}_{2}<90 \%$ and left ventricular MPI is shown in figure 2. TABLE 3 Statistical comparison of the basic measurements
in the different obstructive sleep apnoea syndrome
groups

\begin{tabular}{|c|c|c|c|}
\hline & $\begin{array}{l}\text { Group } 1 \\
\text { versus } 2\end{array}$ & $\begin{array}{c}\text { Group } 1 \\
\text { versus } 3\end{array}$ & $\begin{array}{r}\text { Group } 2 \\
\text { versus } 3\end{array}$ \\
\hline SBP $\mathrm{mmHg}$ & 0.04 & 0.001 & 0.001 \\
\hline DBP mmHg & NS & 0.008 & 0.01 \\
\hline Left atrium $\mathrm{mm}$ & NS & 0.01 & NS \\
\hline IVSD mm & 0.01 & 0.001 & NS \\
\hline PLVWD mm & 0.01 & 0.001 & NS \\
\hline LVM g & 0.001 & 0.0001 & NS \\
\hline LVMI $\mathbf{g} \cdot \mathbf{m}^{-2}$ & 0.002 & 0.001 & NS \\
\hline IVRT ms & 0.01 & 0.01 & NS \\
\hline E/A ratio & 0.01 & 0.01 & NS \\
\hline MPI & 0.01 & 0.01 & NS \\
\hline
\end{tabular}

Data are presented as p-values obtained using the Mann-Whitney U-test. \# group 1: apnoea-hypopnoea index $(A H I)=5-14$, group 2: $A H I=15-29$, and group 3: $\mathrm{AHI} \geqslant 30$. $\mathrm{SBP}$ : systolic blood pressure; $\mathrm{DBP}$ : diastolic blood pressure; IVSD: interventricular septum thickness in diastole; PLVWD: posterior left ventricular wall thickness in diastole; LVM: left ventricular mass; LVMI: left ventricular mass index; IVRT: isovolumic relaxation time; E/A: the ratio of early transmitral/atrial transmitral maximal flow velocities; MPI: myocardial performance index; Ns: nonsignificant. 


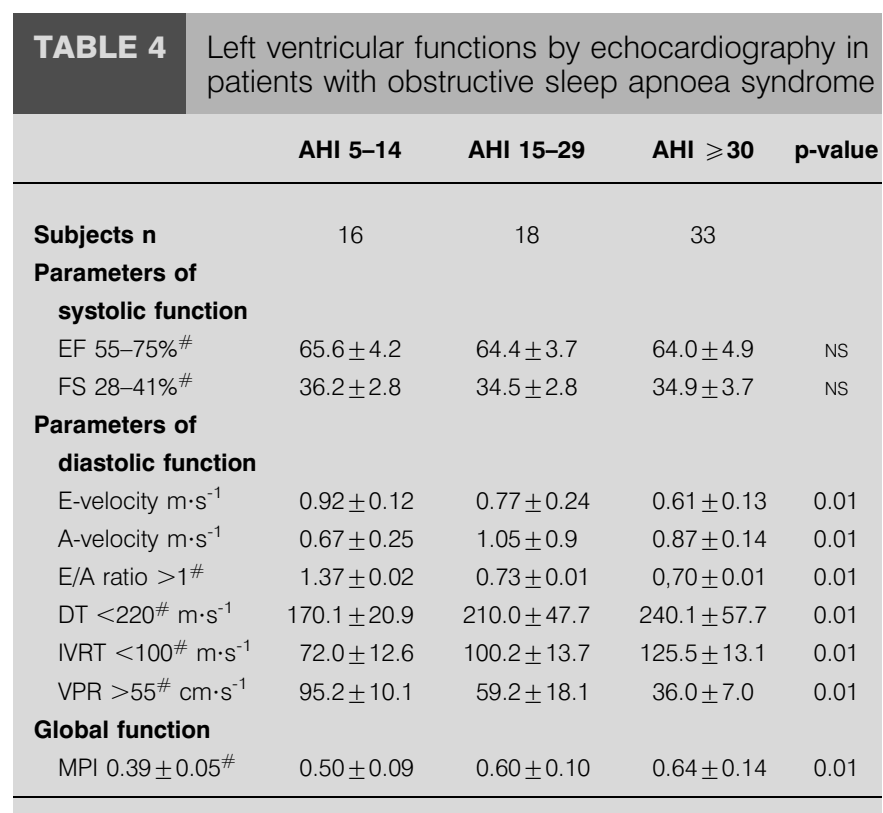

Data presented as mean $\pm \mathrm{SD}$. AHI: apnoea-hypopnoea index; $\mathrm{EF}$ : left ventricular ejection fraction in two dimensions by Simpson's method; FS: fractional shortening; E-velocity: early mitral flow velocity; A-velocity: atrial mitral flow velocity; E/A: ratio of early and atrial mitral flow velocity; DT: mitral deceleration time; IVRT: isovolumic relaxation time; VPR: velocity of mitral flow propagation; MPI: myocardial performance index; NS: not significant. \#: normal values.

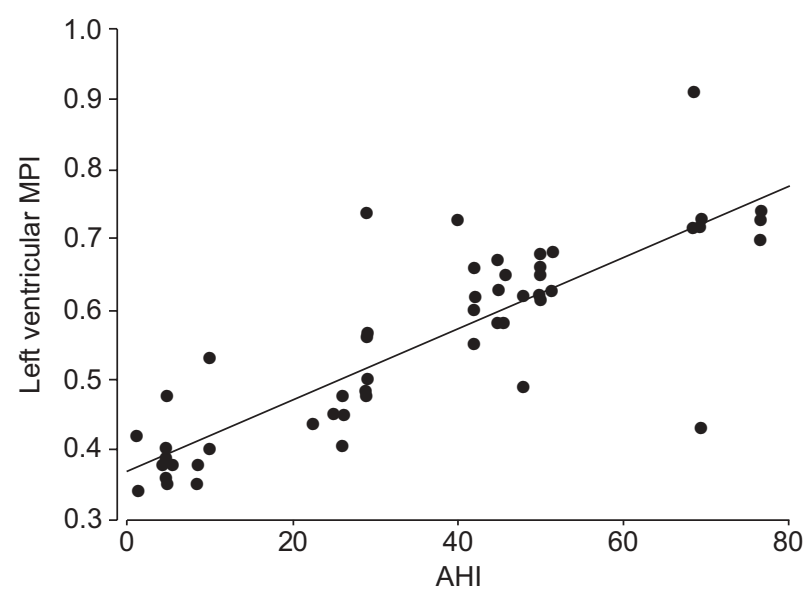

FIGURE 1. Correlation between myocardial performance index (MPI) and apnoea-hypopnoea index $(\mathrm{AHI})$ in obstructive sleep apnoea patients $(\mathrm{r}=0.83$; $p<0.001)$.

\section{DISCUSSION}

Obstructive sleep apnoea syndrome might cause cardiovascular complications, such as heart failure, myocardial infarction arryhthmias, systemic and pulmonary hypertension. Since the left ventricular function was closely related to mortality and morbidity, the current authors aimed to estimate the left ventricular MPI reflecting ventricular global function in OSAS patients.

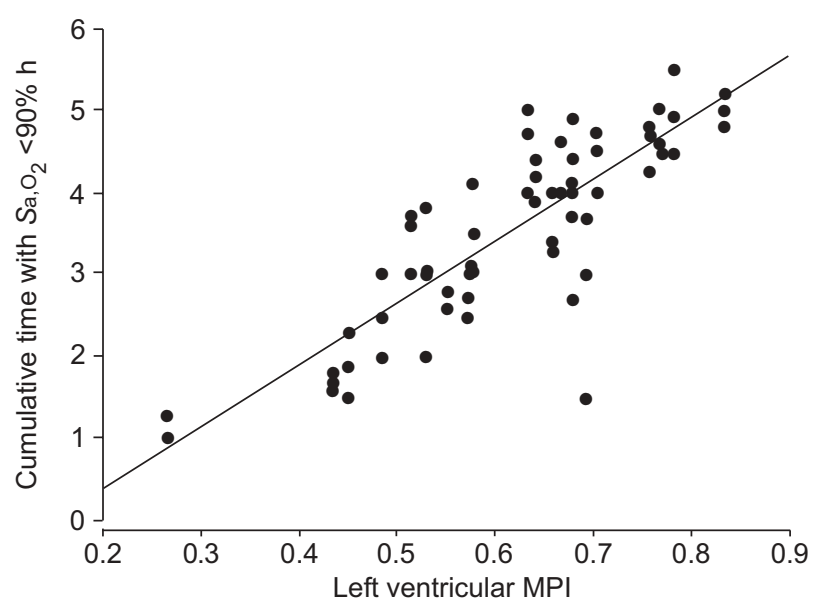

FIGURE 2. Correlation between cumulative time (h) with saturation of nocturnal arterial oxygen $\left(\mathrm{Sa}, \mathrm{O}_{2}\right)$ at $<90 \%$ and ventricular myocardial performance index (MPI).

Patients with OSAS often have coexisting disorders, which have been associated with increased LVM and diastolic dysfunction, such as obesity [28], hypertension [29] and diabetes mellitus [30]. Arterial hypertension, evidence of LVH, high BMI, diabetes mellitus and coronary artery disease are independent predictors of diastolic dysfunction. In the current study, diabetes mellitus and coronary artery disease were excluded, and there were no significant differences in age and BMI of the patients. However, 38 out of 67 OSAS patients were hypertensive and majority of them $(68.4 \%)$ were in the severe group. It is well known that the risk of developing systemic hypertension increases depending on the severity of OSAS [31, 32]. HEDNER et al. [33] showed that nocturnal hypoxemia increases sympathetic stimulation and this might cause systemic hypertension. In patients in the current study, percentage of sleep duration $<90 \% \mathrm{Sa}_{1} \mathrm{O}_{2}$ was the highest in the severe OSAS group, while it was lowest in the mild OSAS group. Therefore, the severe OSAS patients had more hypoxic duration in their sleep compared with moderate and mild OSAS groups. However, ARABI et al. [34] have previously proven that systemic hypertension develops in hypoxic situations in normotensive cases, and, furthermore, they showed a decrease in the adrenergic mediators in patients having continuous positive airway pressure therapy for OSAS. Currently, sleep apnoea is accepted as one of the identifiable causes of hypertension in the Joint National Committee 7 report [10].

In the current study, severe OSAS patients had slight LVH. Moreover, IVS and LVPW diameters, and LVM and LVMI, were slightly higher in patients with severe OSAS, while they were within normal limits in patients with mild and moderate OSAS. The current study does not explain the reason for $\mathrm{LVH}$; however, it could be caused by high blood pressures and/or nocturnal hypoxemia. A multivariate analysis should have been used in a large study population, in order to explain the effects of blood pressures or hypoxemia on LVH. The small number of patients in the present study population is an important limitation when trying to determine that. HEDNER et al. [13] reported that OSAS causes $\mathrm{LVH}$ in a study that compared 61 males with OSAS and 61 male control subjects. The OSAS 
group were heavier and 50\% had systemic hypertension. They reported that LVM was $\sim 15 \%$ higher among normotensive OSAS patients compared with normotensive control subjects, despite comparison of subjects with matching BMI. More recently, NoDA et al. [35] reported echocardiographic evidence of $\mathrm{LVH}$ in $50 \%$ of patients with an $\mathrm{AHI}>20 \cdot \mathrm{h}^{-1}$ compared with $21.4 \%$ in those with an AHI $<20 \cdot \mathrm{h}^{-1}$. In contrast, DAVIES et al. [36] did not find a significant difference in LVM, determined by echocardiography, between 19 patients with OSAS, 19 nonapnoeic snorers, and 38 control subjects matched for age, sex and BMI.

The proposed causes of LVH in OSAS include associated changes in left ventricular afterload, intermittent hypoxemia, and recurrent arousals during sleep. Left ventricular afterload increases during sleep in patients with OSAS because of the combined effects of increased negative intrathoracic pressure, associated with attempted breathing against an occluded upper airway [37], and increased systemic blood pressure [33] associated with elevated sympathetic nervous system activity, hypoxemia, and arousal from sleep [38]. Forced inspiration against increased airway resistance during wakefulness (Mueller manoeuvre) raises aortic transmural pressure, thereby increasing aortic stiffness and left ventricular systolic load [39]. Isovolumic relaxation time of the left ventricle has also been shown to increase in the presence of either hypertension-related or age-dependent increase in aortic stiffness [40].

The current study showed that moderate and severe OSAS patients had LVDD and, also, had global dysfunction diagnosed with increased MPI, although they had normal left ventricular EFs. Since the systolic and diastolic dysfunction frequently coexist, it was shown that a combined measure of left ventricular performance with calculation of MPI might be more reflective of overall cardiac dysfunction than systolic or diastolic measures alone. Diastolic dysfunction can be found in $25 \%$ of asymptomatic hypertensives without LVH, but in $90 \%$ of those having LVH [19]. Reduced early diastolic filling in hypertensive patients has generally been correlated with increased afterload and increased muscle mass. Additionally, hypertension is associated with left atrial enlargement and depression of atrial contractile function. Several mechanisms can impair diastolic function in hypertension [41]. The predominant role of hypertension for the development of diastolic heart failure was initially established by the Framingham Heart Study [42]. Diastolic dysfunction in hypertensive patients can occur even in the absence of structural myocardial abnormalities and usually represents myocyte dysfunction with impaired isovolumic relaxation. Also, the current authors cannot explain exactly the reason of diastolic dysfunction; it could be caused by high blood pressures and/or nocturnal hypoxemia. Left ventricular diastolic filling is a complex event that is influenced by several factors, such as left ventricular relaxation, left ventricular compliance, left atrium contraction force, HR and systemic vascular resistance. Thus, left ventricular dysfunction might be the result of a variety of impairments.

\section{Study limitations}

The small number of patients in the current study population is an important study limitation for determining the effects of blood pressures or nocturnal hypoxemia on LVH and diastolic dysfunction. Also, the sleep clinic population may not reflect the findings in the general community.

\section{Conclusions}

The present study demonstrates that increased apnoeahypopnoea index in patients with obstructive sleep apnoea syndrome may result in left ventricular dysfunction. In this study, a significant positive correlation was shown between myocardial performance index and severity of obstructive sleep apnoea syndrome. Since diastolic dysfunction might be combined with systolic dysfunction, severe obstructive sleep apnoea syndrome patients having diastolic dysfunction might have an increased risk of heart failure. Myocardial performance index is a reproducible, widely applicable and simple noninvasive method for the estimation of left ventricular global function in patients with obstructive sleep apnoea syndrome. It will be important to resolve whether left ventricular dysfunction may be corrected by continuous positive airway pressure treatment aimed at reducing upper airway obstruction in the patients with obstructive sleep apnoea syndrome. Since the ventricular functions provide prognostic information in patients, the results from this study should be further confirmed with several longitudinal studies.

\section{REFERENCES}

1 Guilleminault C, Tilkian A, Dement WC. The sleep apnea syndromes. Ann Rev Med 1976; 27: 465-484.

2 Lattimore JD, Celermajer DS, Wilcow I. Obstructive sleep apnea and cardiovascular disease. J Am Coll Cardiol 2003; 41: 1429-1437.

3 Malone S, Liu PP, Holloway R, Rutherford R, Xie A, Bradley TD. Obstructive sleep apnea in patients with dilated cardiomyopathy: effects of CPAP. Lancet 1991; 338: 1480-1484.

4 Hung J, Whitford EG, Parsons RW, Hillman DR. Association of sleep apnoea with myocardial infarction in men. Lancet 1990; 336: 261-264.

5 Guilleminault C, Connoly S, Winkle RA. Cardiac arrhythmia and conduction disturbances during sleep in 400 patients with sleep apnea syndrome. Am J Cardiol 1983; 52: 490-494.

6 Palomaki H, Partinen M, Erkinjuntti I, Kaste M. Snoring, sleep apnea syndrome and stroke. Neurology 1992; 42: 75-82.

7 Nieto FJ, Young TB, Lind BK, et al. Association of sleepdisordered breathing, sleep apnea, and hypertension in a large community-based study. Sleep Heart Health Study. JAMA 2000; 283: 1829-1836.

8 Peppard PE, Young T, Palta M, Skatrud J. Prospective study of the association between sleep-disordered breathing and hypertension. N Engl J Med 2000; 342: 1378-1384.

9 Weitzenblum E, Krieger J, Apprill M, et al. Daytime pulmonary hypertension in patients with obstructive sleep apnea. Am Rev Respir Dis 1988; 138: 345-349.

10 Chobanian AV, Bakris GL, Black HR, et al. National Heart, Lung, and Blood Institute Joint National Committee on Prevention, Detection, Evaluation, and Treatment of High Blood Pressure and National High Blood Pressure 
Education Program Coordinating Committee. The Seventh Report of the Joint National Committee on Prevention, Detection, Evaluation, and Treatment of High Blood Pressure: the JNC 7 report. JAMA 2003; 289: 2560-2572.

11 Levinson PD, McGarvey ST, Carlisle CC, Eveloff SE, Herbert PN, Millman RP. Adiposity and cardiovascular risk factors in men with obstructive sleep apnea. Chest 1993; 103: 1336-1342.

12 Ancoli-Israel S, Coy T. Are breathing disturbances in the elderly equivalent to sleep apnea syndrome? Sleep 1994; 17: 77-83.

13 Hedner J, Ejnell H, Caidahl K. Left ventricular hypertrophy independent of hypertension in patients with obstructive sleep apnea. J Hypertens 1990; 8: 941-946.

14 Levy D, Garrison RJ, Savage DD, Kannel WB, Castelli WP. Prognostic implications of echocardiographically determined left ventricular mass in the Framingham Heart Study. N Engl J Med 1990; 322: 1561-1566.

15 Sullivan JM, Vander Zwaag RV, el-Zeky F, Ramanathan KB, Mirvis DM. Left ventricular hypertrophy: effect on survival. J Am Coll Cardiol 1993; 33: 508-513.

16 Levy D, Anderson KM, Savage DD, Kannel WB, Christiansen JC, Castelli WP. Echocardiographically detected left ventricular hypertrophy: prevalence and risk factors: the Framingham Heart Study. Ann Intern Med 1988; 108: 7-13.

17 Ganau A, Devereux RB, Pickering TG, et al. Relation of left ventricular hemodynamic load and contractile performance to left ventricular mass in hypertension. Circulation 1990; 81: 25-36.

18 Bonow RO, Udelson JE. Left ventricular diastolic dysfunction as a cause of congestive heart failure. Mechanisms and management. Ann Intern Med 1992; 117: 502-510.

19 Fischer M, Baessler A, Hense HW, et al. Prevalence of left ventricular diastolic dysfunction in the community; Results from a Doppler echocardiographic-based survey of a population sample. Eur Heart J 2003; 24: 320-328.

20 Tei C, Ling LH, Hodge DO, et al. New index combined systolic and diastolic myocardial performance: a simple and reproducible measure of cardiac function: a study in normals and dilated cardiomyopathy. J Cardiol 1995; 26: 357-366.

21 Tei C. New non-invasive index for combined systolic and diastolic function. J Cardiol 1995; 26: 396-404.

22 Johns MW. A new method for measuring daytime sleepiness. Sleep 1991; 14: 540-545.

23 Indications for Polysomnography Task Force, American Sleep Disorders Association Standards of Practice Committee. Practice parameters for the indications for polysomnography and related procedures. Sleep 1997; 20: 406-422.

24 Dingli K, Coleman EL, Vennelle M, et al. Evaluation of a portable device for diagnosing the sleep apnoea/ hypopnoea syndrome. Eur Respir J 2003; 21: 253-259.

25 American Sleep Disorders Association. The Atlas Task Force: Bonnet M, Carley D, Carskadom M, et al. EEG arousals: scoring rules and examples. Sleep 1994; 15: 173-174.

26 American Academy of Sleep Medicine Task Force. Sleeprelated breathing disorders in adults: recommendations for syndrome definition and measurement techniques in clinical research. Sleep 1999; 22: 667-689.
27 American Society of Echocardiography Committee on standards, Subcommittee on Quantitation of TwoDimensional Echocardiograms, Schiller NB, Shah PM, Crawford $\mathrm{M}$, et al. Recommendations for quantitation of the left ventricle by two-dimensional echocardiography. $J$ Am Soc Echocardiogr 1989; 2: 358-367.

28 Lauer MS, Anderson KM, Kannel WB, Levy D. The impact of obesity on left ventricular mass and geometry. The Framingham Heart Study. JAMA 1991; 266: 231-236.

29 Jain A, Avendano G, Dharamsey S, et al. Left ventricular diastolic function in hypertension and role of plasma glucose and insulin. Circulation 1996; 93: 1392-1396.

30 Lee M, Gardin JM, Lynch JC, et al. Diabetes mellitus and echocardiographic left ventricular function in free-living elderly men and women: The Cardiovascular Health Study. Am Heart J 1997; 133: 36-43.

31 Otsuka K. Hypertension and altered cardiovascular variability associated with obstructive sleep apnea. Nippon Rinsho 2000; 58: 1711-1716.

32 Lavie P, Yoffe N, Berger T, Peled R. The relationship between the severity of sleep apnea syndrome and 24-h blood pressure values in patients with obstructive sleep apnea. Chest 1993; 103: 717-721.

33 Hedner J, Ejnell H, Sellgren J, Hedner T, Wallin G. Is high and fluctuating muscle nerve sympathetic activity in the sleep apnoea syndrome of pathogenetic importance for the development of hypertension? J Hypertens 1988; 6: 529-531.

34 Arabi Y, Morgan BJ, Goodman B, Puleo DS, Xie A, Skatrud JB. Daytime blood pressure elevation after nocturnal hypoxia. J Appl Physiol 1999; 87: 689-698.

35 Noda A, Okada T, Yasuma F, Nakashima N, Yokota M. Cardiac hypertrophy in obstructive sleep apnea syndrome. Chest 1995; 107: 1538-1544.

36 Davies RJ, Crosby J, Prothero A, Stradling JR. Ambulatory blood pressure and left ventricular hypertrophy in subjects with untreated obstructive sleep apnea and snoring, compared with matched control subjects, and their response to treatment. Clin Sci 1994; 86: 417-424.

37 Buda AJ, Pinsky MR, Ingles NB Jr, Daughters GT 2nd, Stinson EB, Alderman EL. Effect of intrathoracic pressure on left ventricular performance. $N$ Engl J Med 1979; 301: 453-459.

38 Coccagna G, Mantovani M, Brignanai F, Parchi C, Lugaresi E. Continuous recordings of pulmonary and arterial pressure during sleep in syndromes of hypersomnolence with periodic breathing. Bull Eur Physiopath Respir 1972; 8: 1159-1172.

39 Virolainen J, Kupari M. Age-dependent increase in aortic stiffness during negative intrathoracic pressure in healthy subjects. Am J Cardiol 1993; 71: 878-882.

40 Chang KC, Tseng YZ, Kuo TS, Chen HI. Impaired left ventricular relaxation and arterial stiffness in patients with essential hypertension. Clin Sci Lond 1994; 87: 641-647.

41 Nakashima Y, Nii T, Ikeda M, Arakawa K. Role of left ventricular regional nonuniformity in hypertensive diastolic dysfunction. J Am Coll Cardiol 1993; 22: 790-795.

42 McKee PA, Castelli WP, McNamara PM, et al. The natural history of congestive heart failure: the Framingham study. N Engl J Med 1971; 285: 1441-1446. 